\title{
FREQUENCY OF ELEVATED PLASMA HOMOCYSTEINE (HCY) LEVELS AMONG TYPE 2 DIABETES MELLITUS (T2DM) PATIENTS.
}

1. MBBS, FCPS (Medicine) Associate Consultant Medicine Indus Hospital. Karachi.

2. MBBS, MCPS, FCPS

Assistant Professor Medicine Hamdard University of Medicine and Dentistry.

3. MBBS, FCPS

Assistant Professo

Baqai Medical University

4. MBBS, FPCS

Associate Consultant Medicine Indus Hospital. Karachi.

5. MBBS, FCPS

Assistant Professor Medicine Abbasi Shaheed Hospital.

6. MBBS, FCPS

Professor \& Head Medicine

Abbasi Shaheed Hospital.

Correspondence Address:

Dr. Ajmaal Jami

House No. b708, Block 13,

Gulberg FB Area, Karachi.

ajmaaljami67@gmail.com

Article received on:

20/09/2019

Accepted for publication

$25 / 12 / 2019$

\section{INTRODUCTION}

Diabetes Mellitus is fast growing epidemic. The International Diabetes Federation found, (2007) diabetes affected more than 200 million people worldwide and is expected to affect more than 350 million by 2025. Pakistan is at the seventh position in terms of the highest number of diabetics with 40.9 million diabetic persons. ${ }^{1}$ Its prevalence in Pakistan was $5,217,000$ in 2000 and is expected to become $13,853,000$ by $2030 .{ }^{2}$

Diabetes is an illness with several numerable complications and early mortality, responsible for around $10 \%$ of total expenses of health care in various countries of the world; therefore many researches are done on factors which effect on diabetes control and its complications. Homocysteine is one of these factors. ${ }^{3}$

\begin{abstract}
Tahreem Ansari', Ajmaal Jami², Bushra Rabbani ${ }^{3}$, Ghazanfar ${ }^{4}$, Mahnoor Khalil ${ }^{5}$, Qaiser Jamal ${ }^{6}$
\end{abstract} inclusion criteria were enrolled. Patients with conditions known to cause altered homocystei criteria were enrolled. Patients with conditions known to cause altered homocysteine was analyzed using SPSS version 21 . Results: (90) ninety patients were enrolled in this study during study period with mean age of $61.5 \pm 7.3$ years. Of $(90)$ ninety patients, $45(50 \%)$ were male and $45(50 \%)$ were female with male to female ratio of $1: 1$. Mean duration of diabetes (40\%) patients had Homocysteinemia. Homocysteine levels were of age) $55.5 \% \mathrm{v} / \mathrm{s} 16.6 \%(\mathrm{p}<0.001)$, having diabetes for $>7$ years, $59.2 \% \mathrm{v} / \mathrm{s} 17 \%(\mathrm{p}<0.00004)$ in $21 \% \mathrm{v} / \mathrm{s} 57.4 \%$ cases who were and were not on treatment respectively $(p<0.0004)$, in $22.5 \%$ patients with controlled diabetes and $54 \%$ patients with uncontrolled diabetes respectively statistically significant raised levels in males, $>60$ years of age, non-compliant diabetics, have Key words: $\quad$ Frequency, Homocysteinemia, Stratification, Type 2 Diabetes.

Article Citation: Ansari T, Jami A, Rabbani B, Ghazanfar, Khalil M, Jamal Q. Frequency of elevated plasma homocysteine (Hcy) levels among type 2 Diabetes mellitus (T2DM) patients. Professional Med J 2020; 27(3):635-640. DOI: $10.29309 / T P M J / 2020.27 .3 .4169$ amino acid generated during the metabolism of methionine ${ }^{4,5}$, occurring in almost all human tissues. Elevated levels of homocysteine are associated with vascular disease (in $28 \%)^{6,7}$ by inducing endothelial dysfunction via increased oxidative stress and ADMA (Asymmetric Dimethyl Arginine). ${ }^{8-10}$ In type 2 diabetics, homocysteine levels are significantly increased as compared to healthy subjects ${ }^{11} 31 \%$ of the individuals had laboratory values of $>15 \mu \mathrm{mol} / \mathrm{l} .{ }^{12}$ Homocysteine is known to be recognized as an isolated factor of risk for heart disease in $30 \%{ }^{13}$ with peripheral arterial disease. ${ }^{14} \mathrm{~A}$ study in diabetic patients undergoing dialysis showed elevated homocysteine levels in $85 \% .{ }^{15}$ There is also an association between elevated homocysteine and retinopathy in type 1 and 2 diabetics in $16.5 \% .{ }^{16,17}$ 
A meta-analytical study done by Tao Huang et al. found strong causal association of raised homocysteine (Hcy) values linked with enhanced risk of "Diabetes mellitus Type 2 ". ${ }^{18}$

Work done on this topic internationally shows mixed results; one study shows no difference in homocysteine levels between type 2 diabetics and non-diabetics ${ }^{19}$, others showing increased homocysteine levels in $31 \%^{12}, 39 \%$ of type 2 diabetics vs only $7 \%$ in age matched controls ${ }^{20}$, but to our knowledge there is no study in Pakistan showing the prevalence of hyperhomocysteinemia among type 2 diabetics.

For this reason we plan to do this study in our local population. Thereby strategies could be made to screen such cases and early diagnosis leads to decreased morbidity. The correlation of its level would be most valuable in primary prevention studies.

\section{MATERIAL TOOLS AND METHODOLOGY}

This study was conducted in Department of MEDICINE, comprising of three units with 120 beds at Abbasi Shaheed Hospital from 28 September 2012 to 26 March 2015.

90 patients were enrolled. Type 2 Diabetic patients $>18$ years of age, either sex, controlled ( $\mathrm{HbA} 1 \mathrm{C}$ $\leq 7)$ and uncontrolled $(\mathrm{HbA} 1 \mathrm{C}>7)$ diabetes, diabetes of any duration [long term ( $>7$ years) and early diabetes ( $\leq 7$ years)] were included in this study after informed consent. Patients with type I diabetes Mellitus, those taking pyridoxine, folic acid/ B-12 treatment, antiepileptic or hormone replacement therapy (HRT), with known history of stroke, cardiovascular disease, end stage renal disease, thyroid illness, autoimmune disorders, megaloblastic anemia, pure vegetarians, pregnant females and addicts were excluded from the study. Information regarding patient's age, sex, duration and control of diabetes and treatment was taken at the time of data collection. Patients' fasting (8 hours overnight) serum homocysteine and $\mathrm{HbA1c}$ levels were obtained. Level $>15$ $\mu \mathrm{mol} / \mathrm{L}$ was labeled as elevated homocysteine level. All this information was noted in Performa.
This was a cross sectional study. Non-probability purposive sampling was used for the study. Sample size calculation was taken using WHO Sample Size Determination in Health Studies calculator with 5\% level of significance, $90 \%$ power of the test, $10 \%$ detectable difference, $31 \%{ }^{12}$ population proportion and $52 \%$ anticipated proportion.

\section{Statistical Analysis}

Study data was entered and statistically calculated and assessed using standardized (SPSS) software application 21.0. Frequency along with percentage were computed for all categorical variables like gender, treatment of diabetes, control of diabetes and homocysteinemia. Mean (SD) were computed for all the quantitative variables like age and duration of diabetes. Statistical study test used was Chi-square test which was used to assess significant affiliation of age, gender, duration of diabetes, treatment of diabetes and control of diabetes with homocysteine. P-value $<0.05$ was considered significant. Stratification of variables of study was done with age, gender, duration of diabetes, treatment of diabetes and control of diabetes.

\section{RESULT}

Total of 90 patients were enrolled in this study during study period. The mean (SD) age of enrolled participants is $61.5 \pm 7.3$ years. Of 90 patients, 45 (50\%) were male and 45 (50\%) were female with male to female ratio of 1:1. Mean (SD) duration of diabetes was $6.9 \pm 1.7$ years (Table-I). Of 90 patients 36 (40\%) patients of diabetes had Homocysteinemia.

\begin{tabular}{|l|c|}
\hline \multicolumn{2}{|c|}{ Age in Years } \\
\hline Mean (SD) & $61.5 \pm 7.3$ \\
\hline Min-Max & $48-72$ \\
\hline Duration of diabetes (years) \\
\hline Mean (SD) \\
\hline Min-Max \\
\hline Gender, $\mathbf{n}(\%)$ \\
\hline Male \\
\hline Female \\
\hline Male: Female ratio & $4-9 \pm 1.7$ \\
\hline On treatment, $n$ (\%) & $45(50)$ \\
\hline Controlled diabetes, $n$ (\%) & $1: 1$ \\
\hline \multicolumn{2}{|c|}{ Table-l. Characteristics of study population } \\
\hline
\end{tabular}

Table-I. Characteristics of study population 
Stratified analysis based on age, gender, duration of diabetes, control of diabetes and treatment of diabetes is summarized in Table-II.

\begin{tabular}{|c|c|c|c|c|}
\hline \multirow{3}{*}{ Variables } & \multicolumn{2}{|c|}{ Homocysteniemia } & \multirow{3}{*}{$\begin{array}{l}\text { Total } \\
\text { n (\%) }\end{array}$} & \multirow{3}{*}{ P. Value } \\
\hline & \multirow{2}{*}{$\begin{array}{c}\text { Yes } \\
\text { n (\%) }\end{array}$} & \multirow{2}{*}{$\begin{array}{c}\text { No } \\
\text { n (\%) }\end{array}$} & & \\
\hline & & & & \\
\hline \multicolumn{5}{|c|}{ Age (years) } \\
\hline$<60$ & $06(16.6)$ & $30(83.3)$ & $36(40)$ & \multirow{3}{*}{$<0.001$} \\
\hline$>=60$ & $30(55.5)$ & $24(44.4)$ & $54(60)$ & \\
\hline Total & $36(40)$ & $54(60)$ & $90(100)$ & \\
\hline \multicolumn{5}{|l|}{ Gender } \\
\hline Male & $23(51.1)$ & $22(48.9)$ & $45(50)$ & \multirow{3}{*}{$<0.03$} \\
\hline Female & $13(28.8)$ & $32(71.1)$ & $45(50)$ & \\
\hline Total & $36(40)$ & $54(63.3)$ & $90(100)$ & \\
\hline \multicolumn{5}{|c|}{ Duration of Diabetes (years) } \\
\hline$\leq 7$ & $07(17)$ & $34(83)$ & $41(45.55)$ & \multirow{3}{*}{$<0.00004$} \\
\hline$>7$ & $29(59.2)$ & $20(40.8)$ & $49(54.44)$ & \\
\hline Total & $36(40)$ & $54(60)$ & $90(100)$ & \\
\hline \multicolumn{5}{|c|}{ Treatment of Diabetes } \\
\hline Yes & $09(21)$ & $34(79)$ & $43(47.7)$ & \multirow{3}{*}{$<0.0004$} \\
\hline No & $27(57.4)$ & $20(42.6)$ & 47 (52.2) & \\
\hline Total & $36(40)$ & $54(60)$ & $90(100)$ & \\
\hline \multicolumn{5}{|c|}{ Control of Diabetes } \\
\hline $\mathrm{HbA} 1 \mathrm{c}<7$ & $09(22.5)$ & $31(77.5)$ & $40(44.44)$ & \multirow{3}{*}{$<0.002$} \\
\hline $\mathrm{HbA} 1 \mathrm{c} \geq 7$ & $27(54)$ & $23(46)$ & $50(55.55)$ & \\
\hline Total & $36(40)$ & $54(60)$ & $90(100)$ & \\
\hline \multicolumn{5}{|c|}{ Chi-square test } \\
\hline \multicolumn{5}{|c|}{$\begin{array}{c}\text { Table-II. Stratified analysis of homocysteinemia in } \\
\text { patients with diabetes based on age, gender, duration, } \\
\text { control and treatment of diabetes }\end{array}$} \\
\hline
\end{tabular}

STRATIFIED ANALYSIS OF HOMOCYSTEINEMIAIN PATIENTS WITH DIABETES BASED ON AGE, GENDER, DURATION, CONTROL AND TREATMENT OF DIABETES

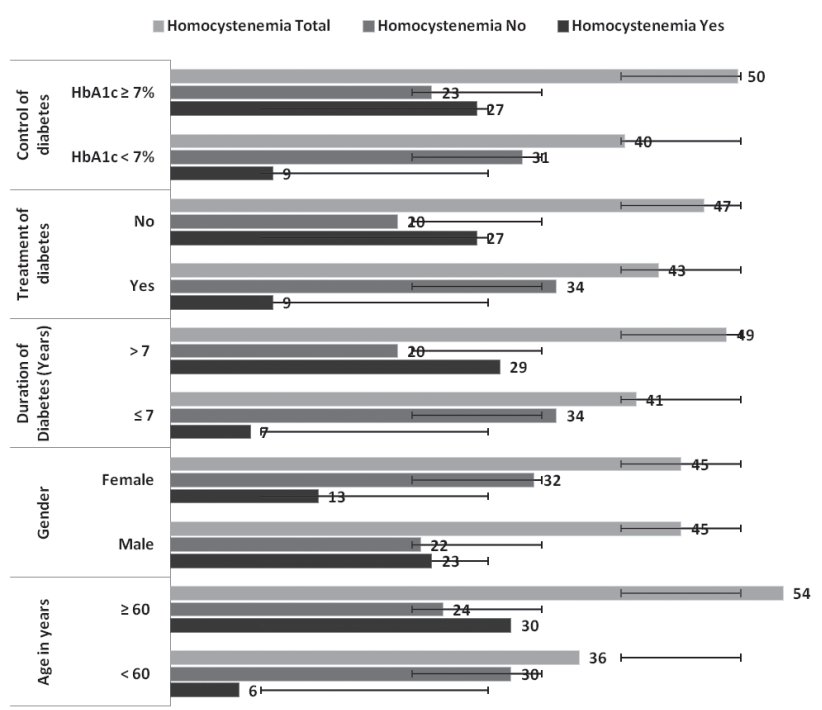

\section{DISSCUSSION}

Increased homocysteine in blood is a known modifiable risk component for heart disease that is not dependent on common major risk contributors like high blood pressure, diabetes, increased cholesterol levels, and smoking. ${ }^{20-23}$

Haung et $\mathrm{al}^{18}$ found that absolute pooled homocysteine level was $0.94 \mu \mathrm{mol} / \mathrm{L}(95 \% \mathrm{Cl}, 0.40$ 1.48) values, more than that in control subjects with measured OR associated with T2DM of 1.29 for for $5 \mu \mathrm{mol} / \mathrm{L}$ increased laboratory values in Hcy suggesting a strong causal association between raised homocysteine levels and development of T2DM. Not only this, increased level of this compound is linked to around 5-year mortality not dependent on other common major risk entities and seems to be a more strong (1.9-fold) risk component for mortality in type 2 diabetic patients in Netherland. ${ }^{24}$

In general population, prevalence data of raised homocysteine levels (>15 $\mu \mathrm{mol} / \mathrm{L})$ ranges between $5 \%$ to $30 \%$ in Canada, Norway and Boston. ${ }^{25-28}$ In a recent study from Canary Islands, hyperhomocysteinemia in Canarian males was found in $32.2 \% .^{29}$ In Pakistan, a study conducted at multicenter including Civil Hospital Karachi, Aga Khan hospital, Armed Forces Institute of Cardiology and Military Hospital, Rawalpindi and National Institute for Cardiovascular Diseases ${ }^{30}$, the prevalence of hyperhomocysteinemia was found to be $57.2 \%$ in young healthy adult cohort, considerably higher than any of the regions.

Talking about type 2 diabetics, researches by Bussychaert $^{12}$ et al, and Hoogeveen et $\mathrm{al}^{24}$, concludethe prevalence ofhyperhomocystenemia to be $31 \%$ and $25.8 \%$ respectively. In contrast to this, Ramachandran et $\mathrm{al}^{31}$ did not find any difference in serum homocysteine levels among diabetic and patients who are in non diabetic control population (levels $2.6886 \mu \mathrm{gm} / \mathrm{ml}$ Vs $2.3037 \mu \mathrm{gm} / \mathrm{ml}$ ). Due to very high prevalence in healthy Pakistani population, the prevalence of homocysteniemia was anticipated even higher in our diabetic population, but surprisingly, the result of our study falls within international reported range. Unfortunately, no locally conducted studies 
on similar topic are available for comparison with our result. Out of 90 patients enrolled in our study, 36(40\%) had hyperhomocysteniemia. The prevalence is slightly higher but is comparable with Bussychaert's results. It was also observed that level of homocysteine was influenced by older age, gender, duration, control and compliance to therapy. Patients who were $>60$ years of age had homocysteinemia in $30(55.5 \%)$ cases $(p<0.001)$. Homocysteinemia was present in $13(28.8 \%)$ females and $23(52.2 \%)$ males $(p<0.03)$ this finding is in accordance with results of Bussychaert's et al and lqbal et $\mathrm{al}^{30}$ where males had higher level (66 v/s 34\% and $89.8 \mathrm{v} / \mathrm{s} 10.2 \%$ respectively). Like our study, significant hyperhomocystenemia in patients with high $\mathrm{HbA1c}$ has also been observed by Ramachandaran et al $(p<0.003)$.

On the other hand, the level was not found to be affected by duration of diabetes in Bussychaert's research, whereas, in Ramachandaran et al and our study, the level was significantly $(p<0.00004))$ influenced by duration of diabetes. The discrepancy could be due to the reason that the cohort in our study had overall shorter duration of diabetes $6.9 \pm 1.7 y r s$ (4-10 years) v/s $14 \pm 9$ years. ${ }^{12}$ The higher prevalence in our study could be a reflection of high levels in our general population $^{30}$ and inclusion of patients who were not taking any treatment.

The difference in prevalence between Pakistani healthy adults and diabetics in our study could be due to factor that we did not include vegetarians, though the criteria to exclude did not include this in the study by lqbal et al. ${ }^{30}$ Secondly, their study was conducted in different centers of two cities representing mixed population.

Homocysteine metabolism is dependent upon sufficient proper stores of vitamins found in dietary sources: vitamin B12 (cobalamin), folic acid and vitamin B6 (pyridoxal phosphate). Deficiency of any of these can lead to hyperhomocsteiemia. This highly prevalent (both healthy and diabetics) risk factor, can be treated by simply correcting the levels of vitamins. ${ }^{24-30}$ Failure to recognize the importance of correction of deficiencies leads to added risk of developing diabetic complications.
Simple addition of these vitamins as fortified food and oral/parenteral replacement can reduce the morbidity and mortality ${ }^{24}$ due to cardiac, renal and vascular complications in diabetics and can reduce the risk of developing of $\mathrm{T}_{2} \mathrm{DM}^{18}$ in normoglycemic individuals.

In future, large scale studies can be done to compare the levels in blood among diabetic and non-diabetic patients, in patients with one v/s multiple confounders, delay in complications with correction of homocysteine levels and preventing the development of homocystenemia in diabetics and decreasing the occurrence of T2DM in normoglycemics.

\section{CONCLUSION}

The overall prevalence of increased homocysteine was high in type 2 diabetic individuals; $40 \%$ of them had laboratory findings $>15 \mu \mathrm{mol} / \mathrm{l}$. Male gender, older age, longer duration, poor control and non-compliance to treatment are associated with increased frequency of elevated homocysteine levels hence making patients more prone to develop complications.

\section{Copyright @ 25 Dec, 2019.}

\section{REFERENCES}

1. Bennett P. New data, fresh perspectives: Diabetes atlas 2007 [46-8].

2. WHO. Programmes and projects and WHO Country and regional data USA: WHO; 2004 [cited 201231 January]. 1st:[Available from: http://www.who.int/ diabetes/facts/world_figures/en/index2.html.

3. Afkhamizadeh M, Ayatollahi H, Abrishami M, Musavi Z, Bonakdaran S, Aboutorabi R, et al., editors. Serum homocysteine levels in diabetes and its relationship to nephropathy. 11th European Congress of Endocrinology, Istanbul, Turkey 2009: Bio Scientifica.

4. Moghadasian MH, McManus BM, Frohlich JJ. Homocyst (e) ine and coronary artery disease: Clinical evidence and genetic and metabolic background. Archives of internal medicine. 1997; 157(20). 2299-308.

5. Ueland PM. Homocysteine species as components of plasma redox thiol status. Clinical chemistry. 1995; $41(3)$. 340-2. 
6. Murphy-Chutorian D, Alderman EL. The case that hyperhomocysteinemia is a risk factor for coronary artery disease. American Journal of Cardiology. 1994; 73(9). 705-7.

7. Clarke R, Daly L, Robinson K, Naughten E, Cahalane S, Fowler B, et al. Hyperhomocysteinemia: an independent risk factor for vascular disease. New England Journal of Medicine. 1991; 324(17). 1149-55.

8. Weiss N. Mechanisms of increased vascular oxidant stress in hyperhomocysteinemia and its impact on endothelial function. Current drug metabolism. 2005; 6(1). 27-36.

9. Antoniades $\mathrm{C}$, Tousoulis D, Marinou $\mathrm{K}$, Vasiliadou C, Tentolouris C, Bouras G, et al. Asymmetrical dimethylarginine regulates endothelial function in methionine-induced but not in chronic homocystinemia in humans: Effect of oxidative stress and proinflammatory cytokines. The American journal of clinical nutrition. 2006; 84(4). 781-8.

10. Björck J, Hellgren M, Råstam L, Lindblad U. Associations between serum insulin and homocysteine in a Swedish population-A potential link between the metabolic syndrome and hyperhomocysteinemia: The Skaraborg project. Metabolism. 2006; 55(8). 1007-13.

11. Zbidi H, Redondo PC, López JJ, Bartegi A, Salido GM, Rosado JA. Homocysteine induces caspase activation by endoplasmic reticulum stress in platelets from type 2 diabetics and healthy donors. Thrombosis and haemostasis. 2010; 103(05). 1022-32.

12. Buysschaert M, Dramais A-S, Wallemacq PE, Hermans MP. Hyperhomocysteinemia in type 2 diabetes: Relationship to macroangiopathy, nephropathy, and insulin resistance. Diabetes care. 2000; 23(12). 181622.

13. Ozmen B, Ozmen D, Turgan N, Habif S, Mutaf I, Bayindir $O$. Association between homocysteinemia and renal function in patients with type 2 diabetes mellitus. Annals of Clinical \& Laboratory Science. 2002; 32(3). 279-86.

14. Howlader H, Ahmed S, Sultana N, Hasan Z, Sadia $U$, Ferdousi S. Serum homocysteine level in type 2 diabetes mellitus with peripheral arterial disease. Bangladesh Journal of Medical Biochemistry. 2013; 6(1). 14-8.

15. C N, Jehan S. Altered plasma Homocysteine levels in End Stage Renal Disease patients on Hemodialysis. Pak Postgrad Med J. 2003; 14(3). 145-50.

16. van Guldener C, Stehouwer CD, editors. Diabetes mellitus and hyperhomocysteinemia. Seminars in vascular medicine; 2002: Copyright@ 2002 by Thieme Medical Publishers, Inc., 333 Seventh Avenue, New.

17. Hoogeveen EK, Kostense PJ, Eysink PE, Polak BC, Beks PJ, Jakobs C, et al. Hyperhomocysteinemia is associated with the presence of retinopathy in type 2 diabetes mellitus: The hoorn study. Archives of Internal Medicine. 2000; 160(19). 2984-90.

18. Huang T, Ren J, Huang J, Li D. Association of homocysteine with type 2 diabetes: A meta-analysis implementing Mendelian randomization approach. BMC genomics. 2013; 14(1). 867.

19. Araki A, Sako $Y$, Ito $H$. Plasma homocysteine concentrations in Japanese patients with non-insulindependent diabetes mellitus: Effect of parenteral methylcobalamin treatment. Atherosclerosis. 1993; 103(2). 149-57.

20. Ueland PM, Refsum H, Brattstrom L. Plasma homocysteine and cardiovascular disease. Atherosclerotic cardiovascular disease, hemostasis, and endothelial function. New York: Marcel Dekker. $1992 ; 183$.

21. Boushey CJ, Beresford SA, Omenn GS, Motulsky AG. A quantitative assessment of plasma homocysteine as a risk factor for vascular disease: probable benefits of increasing folic acid intakes. Jama. 1995; 274(13). 1049-57.

22. Mayer EL, Jacobsen DW, Robinson K. Homocysteine and coronary atherosclerosis. Journal of the American College of Cardiology. 1996;27(3). 517-27.

23. Stehouwer CD, Gall M-A, Hougaard P, Jakobs C, Parving $\mathrm{H}-\mathrm{H}$. Plasma homocysteine concentration predicts mortality in non-insulin-dependent diabetic patients with and without albuminuria. Kidney international. 1999;55(1). 308-14.

24. Hoogeveen EK, Kostense PJ, Jakobs C, Dekker JM, Nijpels G, Heine RJ, et al. Hyperhomocysteinemia increases risk of death, especially in type 2 diabetes: 5-year follow-up of the Hoorn Study. Circulation. 2000;101(13). 1506-11.

25. Lussier-Cacan S, Xhignesse M, Piolot A, Selhub J, Davignon J, Genest Jr J. Plasma total homocysteine in healthy subjects: Sex-specific relation with biological traits. The American journal of clinical nutrition. 1996;64(4). 587-93.

26. Nygård O, Vollset SE, Refsum H, Stensvold I, Tverdal A, Nordrehaug JE, et al. Total plasma homocysteine and cardiovascular risk profile: The Hordaland Homocysteine Study. Jama. 1995; 274(19). 1526-33. 
27. Selhub J, Jacques PF, Wilson PW, Rush D, Rosenberg $\mathrm{IH}$. Vitamin status and intake as primary determinants of homocysteinemia in an elderly population. Jama. 1993; 270(22). 2693-8.

28. Association AD. Diagnosis and classification of diabetes mellitus. Diabetes care. 2010; 33(Supplement 1). S62-S9.

29. Henriquez P, Doreste J, Deulofeu R, Fiuza M, SerraMajem L. Nutritional determinants of plasma total homocysteine distribution in the Canary Islands. European journal of clinical nutrition. 2007; 61(1). 111.
30. Iqbal P, Lindblad BS, Mehboobali N, Yusuf FA, Khan $\mathrm{AH}$, Iqbal SP. Folic acid and vitamin B6 deficiencies related hyperhomocysteinemia in apparently healthy Pakistani adults; is mass micronutrient supplementation indicated in this population. Journal of the College of Physicians and Surgeons Pakistan. 2009;19(5):308.

31. Ramachandran L, Negi N, Gupta B. Prevalence of hyperhomocysteinaemia in type 2 diabetes mellitus and its correlation with its complications. J Ind Aca Clin Med. 2012; 13(4). 277-81.

\begin{tabular}{|c|c|c|c|}
\hline \multicolumn{4}{|c|}{ AUTHORSHIP AND CONTRIBUTION DECLARATION } \\
\hline Sr. \# & Author(s) Full Name & Contribution to the paper & Author(s) Signature \\
\hline 1 & Tahreem Ansari & 1st Author & Tahreerer \\
\hline 2 & Ajmaal Jami & 2nd Author & A-Tamis \\
\hline 3 & Bushra Rabbani & 3rd Author & Gheyafee \\
\hline 4 & Ghazanfar & 4th Author & Busher \\
\hline 5 & Mahnoor Khalil & 5th Author & Malwoor \\
\hline 6 & Qaiser Jamal & 6th Author & Qajertzanal \\
\hline
\end{tabular}

